\title{
Role of phosphoinositide 3-kinase in the autophagic death of serum-deprived PC12 cells
}

\author{
A. Guillon-Munos, M. X. P. van Bemmelen and P. G. H. Clarke \\ Département de Biologie Cellulaire et de Morphologie (A. Guillon-Munos, P. G. H. Clarke), and Département de \\ Pharmacologie et de Toxicologie (M. X. P. van Bemmelen), University of Lausanne, Switzerland
}

\begin{abstract}
The death of serum-deprived undifferentiated PC12 cells shows both autophagic and apoptotic features. Since it is still controversial whether the autophagy is instrumental in the cell death or a mere epiphenomenon, we tested the effects of inhibiting the autophagy by a variety of phosphoinositide 3-kinase inhibitors, and provided evidence that the autophagy, or a related trafficking event, is indeed instrumental in the cell death. Furthermore, by comparing the effects of PI3-K inhibition and caspase-inhibition on autophagic and apoptotic cellular events, we showed that in this case the autophagic and apoptotic mechanisms mediate cell death by parallel pathways and do not act in series.
\end{abstract}

Keywords: apoptosis; autophagic cell death; LY294002; PI3kinases.

\section{Introduction}

Autophagy is the mechanism by which cells degrade their own cytoplasmic content using the lysosomal machinery. There are several forms of it, including microautophagy, the direct capture of tiny portions of cytosol by invagination of lysosomal membranes, and macroautophagy, which involves the engulfment of sizeable regions of cytoplasm, including organelles, by phagosomes (derived from the endoplasmic reticulum and perhaps other sources such as the trans-Golgi network) ${ }^{1}$ followed by their fusion with lysosomes. These (and other) forms of autophagy are involved in the normal turnover of cell contents and are enhanced by cellular stresses, against which they provide protection, e.g. by replenishing the pool of free amino

Financial support: grants 31-50598.97 and 31-61736.00 from the Swiss National Science Foundation.

Correspondence to: Peter G.H. Clarke, Département de Biologie Cellulaire et de Morphologie (DBCM), University of Lausanne, Rue du Bugnon 9, CH-1005 Lausanne, Switzerland. Tel: +4121 692 5120; Fax: +41 21692 5105; e-mail: Peter.Clarke@unil.ch acids in the case of amino acid depletion, ${ }^{2,3}$ or by eliminating damaged proteins. ${ }^{4}$

Despite the life-promoting roles of autophagy, macroautophagy has also been associated with cell death, and the term autophagic cell death is used as a classification for dying cells undergoing intense macroautophagy. ${ }^{5}$ This type of cell death occurs frequently during embryonic development and is probably the most common type of cell death in insect metamorphosis, ${ }^{5}$ but (macro)autophagic features are also associated with many cases of pathological cell death including heart failure, ${ }^{6}$ excitotoxicity ${ }^{7}$ and neurodegenerative diseases including Alzheimer's disease. ${ }^{8}$ In its pure form, autophagic cell death is caspase-independent and is clearly distinct from canonical apoptosis, ${ }^{6,9-11}$, although mixed forms can occur that show both autophagic and caspase-related apoptotic features. ${ }^{12-16}$

While the existence of autophagic cell death as a distinct morphological type is beyond dispute, the question of whether the autophagy is instrumental for the cell death is still not entirely resolved (see Discussion). The fact that 3-methyladenine (3-MA), which prevents the formation of autophagic vacuoles, inhibits both the pure autophagic cell death and the mixed form in numerous situations argues in favour of an instrumental role, ${ }^{12,15}$ but since the specificity and mode of action of 3-MA are unclear, more evidence is needed.

Since one effect of 3-MA is to inhibit phosphoinositide 3-kinases (PI3-K), and since better characterized specific inhibitors of PI3-K are available and are known to inhibit autophagy ${ }^{2,3}$ we here test the effects of the PI3-K inhibitors LY294002 (and, in pilot experiments, wortmannin) as well as 3-MA, on serum-deprived PC12 cells, whose cell death is known to have autophagic as well as apoptotic features. ${ }^{13,14,17}$ We show that these compounds inhibit (macro)autophagy and protect against the cell death, suggesting that autophagy does indeed play a causal role in it, although we also provide evidence for a caspase- 3 related apoptotic mechanism acting probably in parallel. 


\section{Materials and methods}

\section{Cell cultures and pharmacological inhibitors}

PC12 cells were cultured in Dulbecco's Modified Eagle's Medium (DMEM, Life Technologies) containing a high level of glucose $(4,5 \mathrm{~g} / \mathrm{L})$ supplemented with $10 \%$ heatinactivated foetal calf serum (Amimed). Before starvation, cells were washed four times in serum-free DMEM by centrifugation and plated at $1 \times 10^{6}$ cells/well in six-well plates. In each experiment, cells were cultured in the presence of serum (as controls), or without serum, or without serum but in the presence of variable concentrations of the following inhibitors: LY294002 (10-100 $\mu \mathrm{M}$; Sigma) from a $10 \mathrm{mM}$ stock solution in DMSO; or 3-MA (5$15 \mathrm{mM}$; Sigma) from a $500 \mathrm{mM}$ stock solution in ethanol; or the pan-caspase inhibitor z-VAD.fmk (50-100 $\mu \mathrm{M}$; Bachem) from a $100 \mathrm{mM}$ stock solution in ethanol; or, in a few pilot experiments, wortmannin (10nM-1 $\mu \mathrm{M}$; Sigma) from a $1 \mu \mathrm{M}$ stock solution in DMSO. When tested on control cells, these compounds had no toxic effect at the concentrations used.

\section{Cytochemistry and immunocytochemistry}

Acid phosphatase activity. Cells cultured on poly-L-lysinecoated glass coverslips under various experimental conditions were washed three times in water prior to fixation in $1 \%$ paraformaldehyde: $0.5 \%$ glutaraldehyde for $15 \mathrm{~min}$ utes at room temperature followed by 4 washes in phosphate buffered saline (PBS). The cells were then assayed for acid phosphatase activity using $\beta$-glycerophosphate as substrate with lead nitrate as donor, followed by revelation with ammonium sulphide, ${ }^{18,19}$ and mounted in a 1:1 PBS:glycerol mounting medium. Cells with clumped acid phosphatase (AcP) activity (presumably secondary lysosomes) were then counted (see later for statistics).

Immunocytochemistry was done on cells cultured on coverslips and fixed with $3 \%$ formaldehyde in PBS containing $3 \%$ sucrose. The cells were permeabilised with $0.2 \%$ triton in PBS and incubated in blocking solution (milk) and finally with the antibodies following published protocols (ref. ${ }^{20}$ for the 6C4 monoclonal antibody against lysobiphosphatidic acid (LBPA), a gift from Prof. J. Gruenberg; and ref. ${ }^{21}$ for polyclonal anti-Vps34, a gift from Prof. T Yoshimori). The secondary antibody used to detect LBPA was coupled to FITC and the one to detect Vps34 was coupled to CY3. The sections were viewed by confocal microscopy.

Nissl staining. Cells cultured on poly-L-lysine-coated glass coverslips were washed in PBS, fixed in $4 \%$ paraformaldehyde for 20 minutes at room temperature and the coverslips immersed in $0.1 \%$ cresyl violet for 15 seconds, washed in PBS and mounted in PBS:glycerol mounting medium.

\section{Electron microscopy}

Cells cultured in Petri dishes were washed 4 times in cold Sorensen's phosphate buffer, fixed in $2 \%$ glutaraldehyde in the same buffer for 1 hour at $4^{\circ} \mathrm{C}$, washed 3 times for 10 minutes at $4^{\circ} \mathrm{C}$ before being scraped and pelleted for embedding in $1 \%$ low melting point agarose to enable small pieces to be cut; post-fixation was in $2 \%$ osmium tetroxide, followed by dehydration in graded ethanols and embedding in Epon. Thin sections were cut using an ultramicrotome and contrasted with uranyl acetate and lead citrate.

\section{Cell counts and cell death assay}

Surviving cells (all adherent cells, both healthy and pyknotic) were counted in Nissl-stained preparations, and the ratio of pyknotic cells versus normal ones was estimated from the same preparations. In both cases, at least 200 cells were counted for each condition and the onetailed unpaired $t$ test was used for statistical evaluation of the results. In each experiment, control cells are cells cultured in a serum-containing medium and the percent survival is the ratio between the total number of cells in serum free medium and the total number in the control condition.

Cumulative cell loss was evaluated by measuring lactate dehydrogenase (LDH) released into the culture medium with the Cytotox 96 assay kit (Promega). Three experiments were performed, comparing LY294002-treated serum-deprived cultures with untreated (but serumdeprived) controls, involving respectively 2,3 and 5 pairs of cultures. In each experiment the percent protection was calculated.

\section{Immunoblotting to reveal caspase-3 activation}

Cells cultured in Petri dishes were lysed in tris-buffered saline (TBS) containing 0,1\% Triton-X100 and lysates kept at $-20^{\circ} \mathrm{C}$ before clearance of cell debris by centrifugation at $14.000 \mathrm{rpm}$, at $4^{\circ} \mathrm{C}$, for 10 minutes. Protein concentration was estimated with the Bradford protocol and $25 \mu \mathrm{g}$ of total protein in Laemmli buffer was loaded on $12 \%$ acryl-bisacrylamide gels and subjected to SDSPAGE. After transfer on nitrocellulose membranes, the blots were blocked in TBS/milk, incubated with antibodies against caspase-3 (rabbit IgG, R\&D Systems, 1:1000), or cleaved caspase-3 (rabbit, Cell Signaling, specific for the large fragment after cleavage at Asp175; 1:5000) or $\alpha$-tubulin (monoclonal IgM, Santa Cruz, 1:500). HRPcoupled secondary antibodies were from Vector Laboratories. Detection of the signals was performed using the Amersham ECL reagent. For quantification of the blots, 
X-ray films exposed to the ECL signals were scanned on an EpsonExpression 1680 Pro flatbed scanner at $300 \mathrm{dpi}$ and 16 bit gray levels. Images were stored as TIF files. Densitometric analysis of the bands corresponding to the cleaved form of Caspase- $3(17+19 \mathrm{kDa})$ was carried out using QuantityOne v4.2.3 software (Biorad). Cleaved caspase levels after $24 \mathrm{~h}$ serum starvation in the absence of drugs were used to normalize all other values within each independent experiment.

\section{Results}

\section{Electron microscopy}

Autophagy is characterised by the accumulation of cytoplasmic vacuoles containing cell debris. To visualize this phenomenon in the dying PC12 cells, we performed electron microscopy on control and serum-deprived cells after
16 and $24 \mathrm{~h}$ of culture. At $16 \mathrm{~h}$ we could indeed determine the presence of empty vacuoles $(\mathrm{V})$ and autophagic vacuoles (Av) as described by Ohsawa et al. ${ }^{14}$ in serumdeprived cells (Figure 1). Already at $16 \mathrm{~h}$ of serum-free culture, some of the cells showed condensed nuclei (as is seen in apoptosis), but this phenotype was more prominent at $24 \mathrm{~h}$ (data not shown). ${ }^{14,17}$ Thus, the ultrastructure suggested the activation of autophagic and apoptotic pathways, and additional necrotic mechanisms cannot be excluded in view of the empty vacuoles.

\section{Autophagic and apoptotic features of PC12 cells at different times of serum-free culture}

As a straightforward, light microscopic indicator of the presence of autolysosomes we used acid phosphatase (AcP) cytochemistry, specific for the lysosomal compartment. With this method, primary lysosomes, if detected at all,

Figure 1. Ultrastructural appearance of healthy and dying cells. (a) 3 cells cultured for $16 \mathrm{~h}$ in complete medium, with a healthy morphology; (b) and (c) one cell cultured in serum-free medium for $14 \mathrm{~h}$ at two different magnifications. $\mathrm{V}$ : empty vacuoles; Av: autophagic vacuoles. Bars: (a) $2 \mu \mathrm{m}$; (b) $1 \mu \mathrm{m}$; (c) $0.2 \mu \mathrm{m}$.

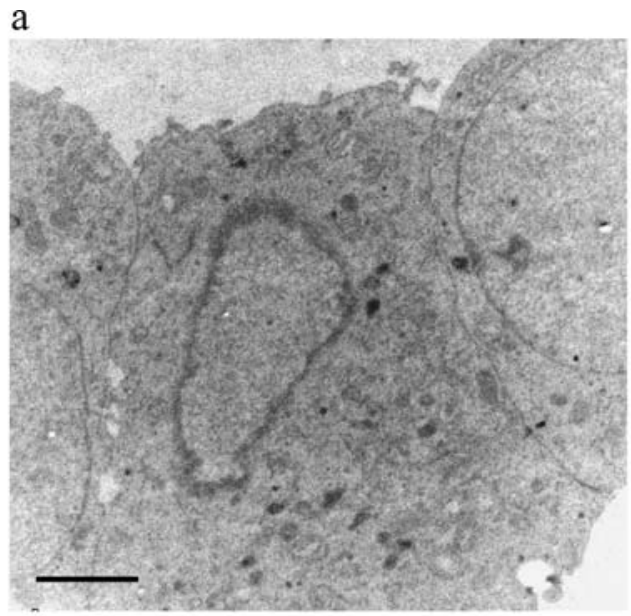

b

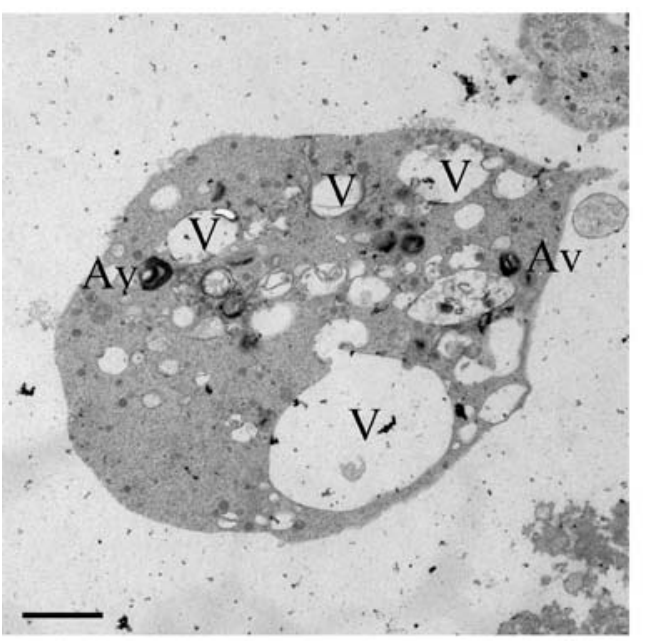

$\mathrm{c}$

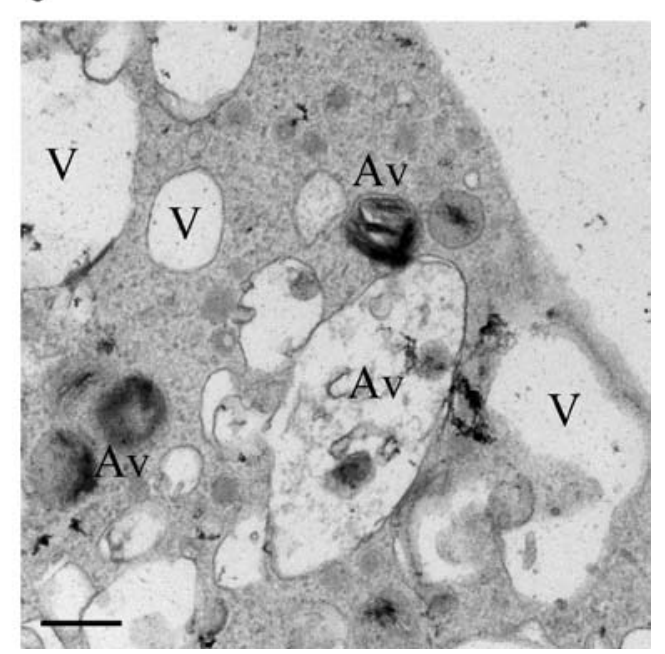




\section{A. Guillon-Munos et al.}

appear as minute spots of reaction product, but larger clumps $(>1 \mu \mathrm{M})$ indicate the presence of secondary lysosomes such as those occurring in autophagic cell death. ${ }^{18,22}$ Already at $12 \mathrm{~h}$ of serum-free culture, there was an increase in the percentage of cells labelled for the active enzyme, but the maximal percentage was at $16 \mathrm{~h}$ (Figure $2 \mathrm{~b}$ ). The reaction product was granular, and localized mainly in the perinuclear region (Figure 2a). As a marker of late endosomes, an antibody against lysobiphosphatidic acid (LBPA) ${ }^{20}$ was also used and showed the appearance of granular cytoplasmic labelling mainly after $12 \mathrm{~h}$ of culture without serum whereas no labelling was detectable in complete medium (data not shown). These results confirm the accumulation of acidic compartments in the dying PC12 cells, indicating the occurrence of (macro)autophagy. After $16 \mathrm{~h}$ serum deprivation, the percentage of AcP-positive cells decreased despite the fact that the number of dying cells increased.

Many of the serum-deprived cells were also shrunken, with condensed, darkly-stained nuclei (henceforth:

Figure 2. Time-courses of markers of the two kinds of cell death following serum deprivation. (a) AcP reaction in cells cultured for $16 \mathrm{~h}$ with (control) or without serum. Arrowheads show secondary lysosomes. Bar, $10 \mu \mathrm{m}$; (b) Percentages of cells with AcP-positive granules as percent of all cells at different times of culture ( $+/-\mathrm{SD}) n=4,{ }^{*} p<0.05$ compared to control (one-tailed unpaired $t$-test). (c) Percentages of pyknotic cells at different times of culture as percent of all cells $(+/-\mathrm{SD}) 5 \leq n \leq 8,{ }^{*} p<0.05$ compared to control (one-tailed unpaired $t$-test).

a

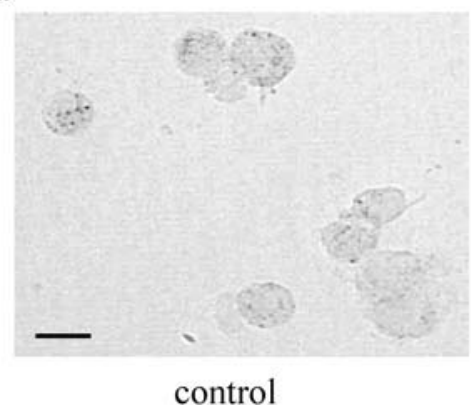

control

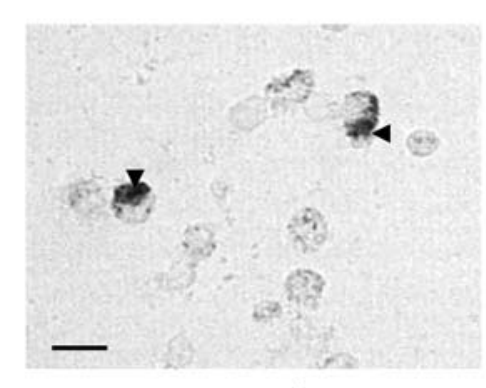

serum free

$\mathrm{b}$

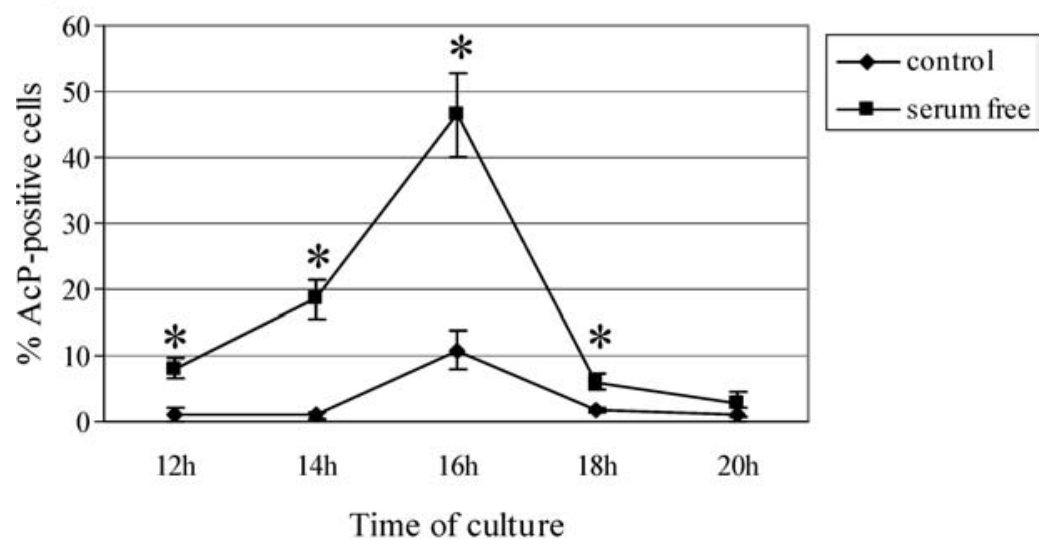

$\mathrm{c}$

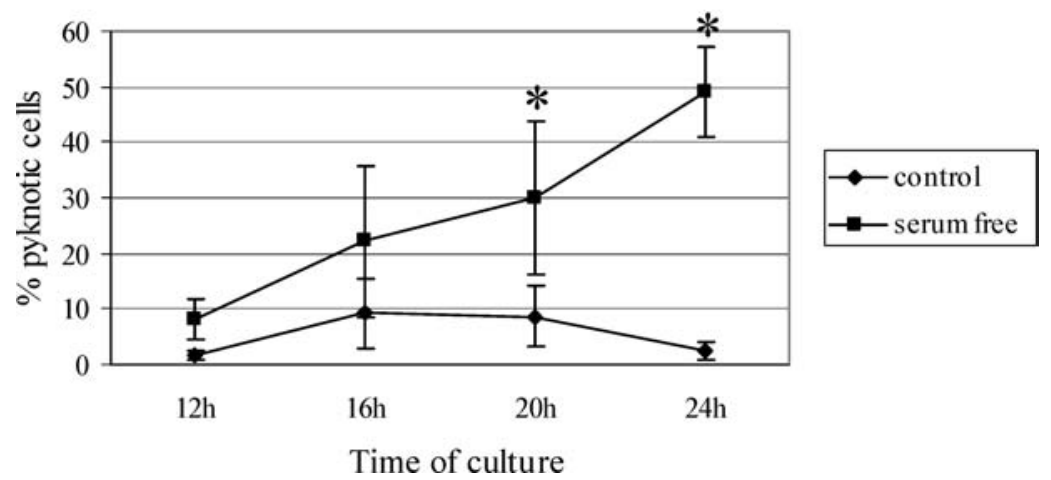


"pyknotic cells"). Although not strictly specific for apoptosis, this morphology is a characteristic feature of it. The proportion of pyknotic cells increased steadily with the time in serum-free culture, reaching $50 \%$ at $24 \mathrm{~h}$ (Figure $2 \mathrm{c}$ ), and caspase- 3 was activated in parallel (see below and Figure 6a, b).

\section{Effects of inhibiting PI3-K or caspases}

Acid phosphatase (AcP) histochemistry. Since PI3-K inhibitors inhibit autophagy, ${ }^{2}$ we examined in our model whether they affect the appearance of acid phosphatase reactivity. Indeed, the proportion of AcP-positive cells was reduced by culturing in the presence of the PI3$\mathrm{K}$ inhibitors LY294002 or 3-MA (Figure 3a). This observation suggests a role of PI3-K activity in the formation of the acidic compartments. In contrast, the acid phosphatase labelling was not affected by treatment with the pan-caspase inhibitor z-VAD.fmk (Figure 3a).

Pyknotic cell counts. In parallel to the decrease in AcPpositive cells, we observed a decrease in pyknosis in the presence of either LY294002 or z-VAD.fmk (Figure 3b).
In pilot experiments, protection similar to that with LY294002 was seen also with wortmannin (100 nM or $1 \mu \mathrm{M}$, but not with $10 \mathrm{nM}$ ), but for the main quantitative evaluations LY294002 was preferred because wortmannin is unstable and needs to be renewed every few hours, which is inconvenient in $24 \mathrm{~h}$ experiments. Since cellular pyknosis has frequently been reported to be prevented by caspase inhibitors, its decrease in the presence of z-VAD.fmk was expected. The effect of the PI3$\mathrm{K}$ inhibitor is more surprising and suggests the existence of a link between autophagy and apoptosis in the cells.

Quantification of cell survival. Since counts of pyknotic cells indicate the rate of cell death rather than its total extent, ${ }^{23}$ we evaluated cell survival by counting the adhering cells after $24 \mathrm{~h}$ serum deprivation. A dose-response trial of LY294002 showed strong protection against cell death (Figure 4a), the maximal effect being at $50 \mu \mathrm{M}$. At this concentration, the cell loss was reduced from $58 \%$ to $17 \%$, a protection of $71 \% .10 \mathrm{mM} 3-\mathrm{MA}$, a standard dose used to inhibit autophagy $\mathrm{y}^{2,12,15}$ reduced the cell loss just over $40 \%$, as did $100 \mu \mathrm{M} z$-VAD.fmk (Figure $4 \mathrm{~b}$ ). The protection with $50 \mu \mathrm{M}$ LY294002 was confirmed with an $\mathrm{LDH}$ assay, which showed an 85 ( $\pm 17 \mathrm{SD}) \%$ reduction

Figure 3. Effects of pharmacological inhibitors. (a) Effects on the percentages of AcP-positive cells after $16 \mathrm{~h}$ of culture $(+/-\mathrm{SD}) n=4$.

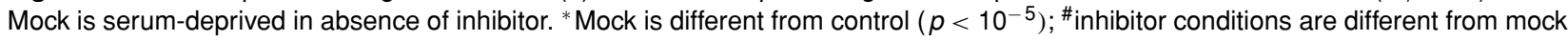
$(p<0.005)$. (b) Effects on the percentages of pyknotic cells after different times of serum deprivation (+/-SD) $5 \leq n \leq 8,{ }^{*} p<0.05$ compared to serum-free. One-tailed unpaired $t$-test was used in each case.

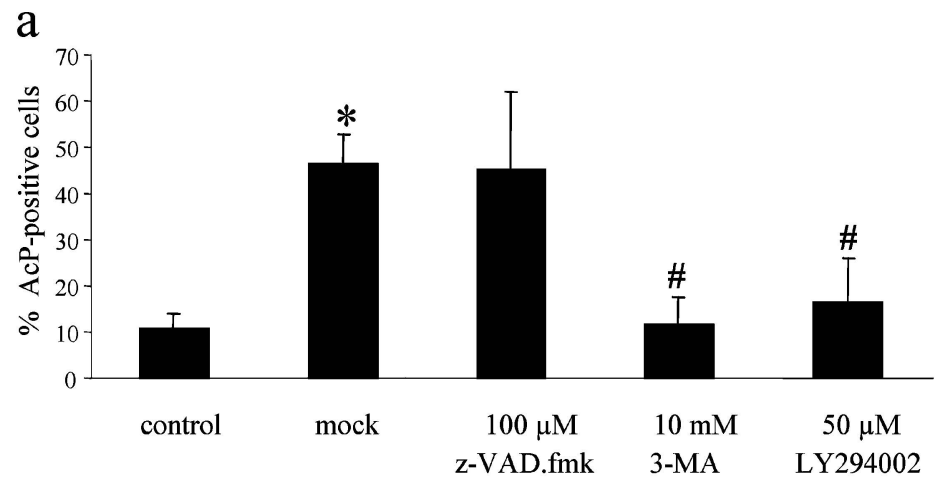

b

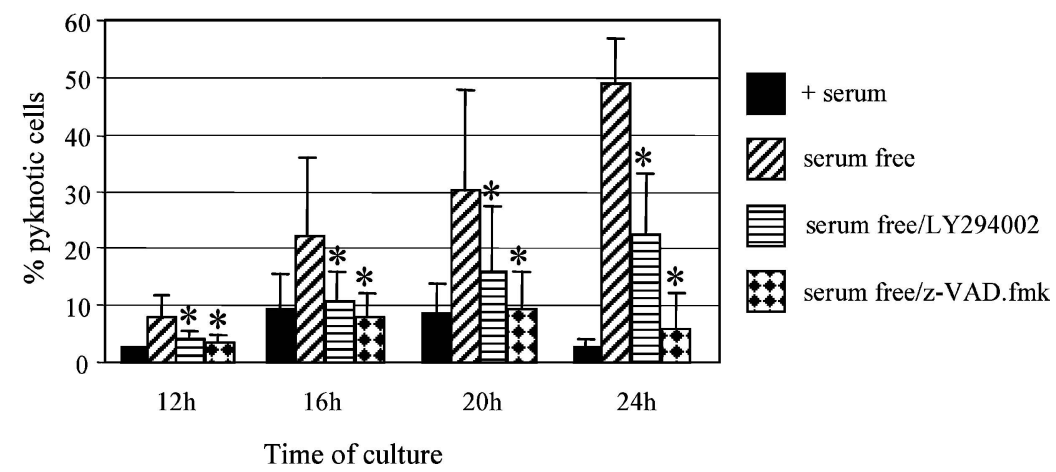


Figure 4. Cell survival after $24 \mathrm{~h}$ of serum deprivation. (a) Percentages of surviving adherent cells relative to the control (serumdeprived without inhibitor) for different doses of LY294002 ( \pm SD) $4 \leq n \leq 13 ;{ }^{*} p=0.002$; ${ }^{* *} p=4 \times 10^{-5}$. (b) Effects of 3-MA $(10 \mathrm{mM})$, LY294002 $(50 \mu \mathrm{M})$ and z-VAD.fmk $(100 \mu \mathrm{M})$ on percentages of surviving adherent cells $( \pm \mathrm{SD}) 4 \leq n \leq 13,{ }^{*} p=0.002$, ** $p=8.9 \times 10^{-5}$.

\section{a}

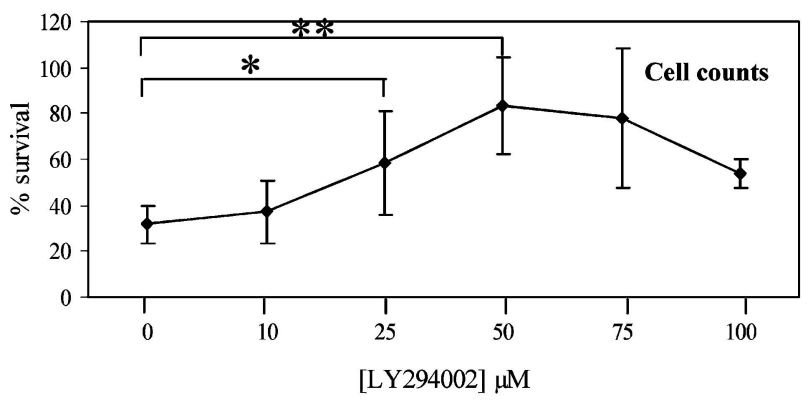

b

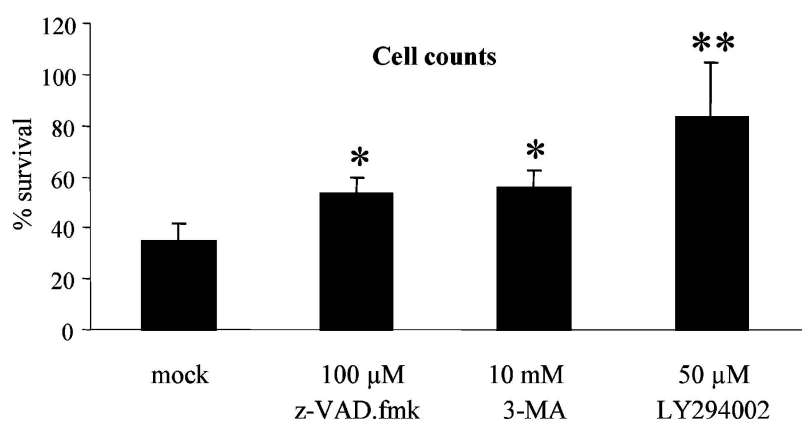

in LDH-release $(n=3, p=0.007$, one-tailed paired $t$-test). The protective efficacy of LY294002 and 3-MA suggests that inhibiting the formation of autophagic vacuoles protects against cell death in this model and indicates that PI3-K plays a role in this cell death process, in accordance with previous results on other cell lines and death stimuli. ${ }^{12,15}$

\section{VPS34 immunocytochemistry}

Since the protective effects of the PI3-K inhibitors would be most easily explained in terms of an inhibition of class III PI3-K, we investigated the expression of Vps34, which is the only mammalian class III PI3-K, by immunocytochemistry. As shown in Figure 5, Vps34 was indeed expressed in the cells. It was mainly cytoplasmic, as predicted from previous reports of it being localized mainly in the Trans-Golgi network. ${ }^{21}$ However, in a minority of cells the labelling was restricted to the perinuclear region (Figure 5), and, strikingly, the proportion of such cells increased with serum deprivation. Counts at $16 \mathrm{~h}$ of culture in 4 separate experiments showed a tenfold increase from
$1.5 \% \pm 0.5 \%$ SEM to $15.0 \% \pm 3.8 \% \mathrm{SEM}$ as a result of serum deprivation.

\section{Caspase-3 activation}

In view of the protective effects of the pan-caspase inhibitor z-VAD.fmk (see above) and of a relatively specific caspase- 3 inhibitor (ac-DEVD-CHO), ${ }^{13}$ we examined caspase- 3 activity by immunoblotting at different times of culture without serum and found that the protease is already activated at $12 \mathrm{~h}$, and continues to be so until at least $24 \mathrm{~h}$ of culture, whereas it remained inactive in the presence of serum (Figure 6a and b). As expected, the presence of $\mathrm{z}$-VAD.fmk in the culture medium totally inhibited caspase- 3 activation, presumably by inhibiting upstream caspases that activate caspase-3 (Figure 6a-c); but, interestingly, the PI3-K inhibitors (LY294002 and 3-MA) enhanced both its activation and its expression (Figure $6 \mathrm{a}-\mathrm{c}$ ) despite the fact that they reduced the cell death.

\section{Discussion}

\section{Prevention of cell death by inhibition of PI3-K}

The main conclusion of this work is that the death of serum-deprived PC12 cells, which has autophagic features, is diminished not only by 3-MA but by the specific PI3-kinase inhibitor LY294002 (and wortmannin in pilot experiments). This same cell death had already been shown to be inhibited by 3-MA in the same sub-line of PC12 cells. ${ }^{17}$ Although 3-MA was introduced simply as an inhibitor of autophagy, this action is now believed to be due to inhibition of PI3-K ${ }^{2}$ including class III PI3-K. ${ }^{3}$ Since class III PI3-K activity is known to be necessary for autophagy, ${ }^{3,24}$ whereas class I PI3-K activity inhibits autophagy, ${ }^{3}$ it seemed plausible that the protective action of 3-MA might be due to its inhibition of class III PI3$\mathrm{K}$ (which is encoded by a single gene, the mammalian homologue of VPS34). ${ }^{25}$ However, a problem with the extensive 3-MA data is the high concentration (10 mM) required to protect cells, and the lack of evidence concerning its specificity (apart from it being known not to inhibit protein synthesis). ${ }^{26}$

LY294002 (and wortmannin), unlike 3-MA, have been characterized in detail, and are known to be relatively specific for PI3-K at concentrations of up to $50 \mu \mathrm{M}$ LY294002 or $100 \mathrm{nM}$ wortmannin. ${ }^{27,28}$ Unfortunately, there is little available data concerning the actions of LY294002 and wortmannin on different classes of PI3$\mathrm{K}$ in mammalian cells, but there seems to be little class-related specificity. ${ }^{29}$ In fission yeast the sole PI3$\mathrm{K}$ (VPS34, which has class III properties) has an IC50 to 
Figure 5. Vps34 immunocytochemistry. (a) +serum $16 \mathrm{~h}$ phase; (b) +serum $16 \mathrm{~h}$ confocal; (c) - serum $16 \mathrm{~h}$ phase; (d) - serum $16 \mathrm{~h}$ confocal. Arrow indicates a serum-deprived cell with ring-shaped perinuclear immunostaining. Bar, $10 \mu \mathrm{m}$.
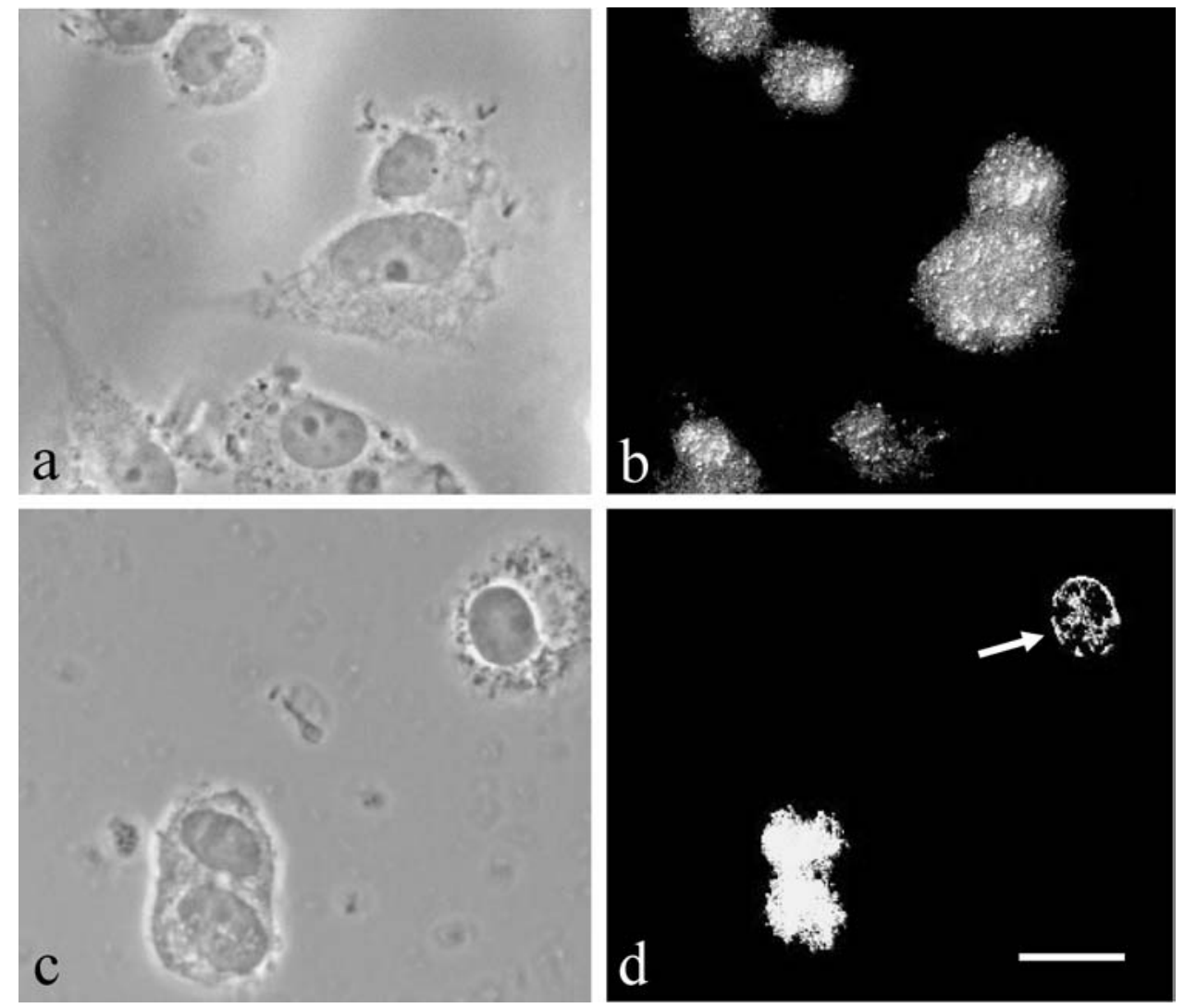

inhibition by LY294002 of $35 \mu \mathrm{M},{ }^{30}$ which is higher than for class I PI3-K in mammals but matches the LY294002 concentrations required for protection in the present experiments.

Thus, in view of the concordant results with our 3 different PI3-K inhibitors (the 2 specific ones and 3-MA), it seems reasonable to conclude that the protection mediated by these drugs was indeed due to inhibition of PI3-K. It is unfortunate that class-specific inhibitors are not available, and the fact that both the major PI3-K classes (I and III) were inhibited makes it remarkable that any protection was obtained, because class I PI3-K is well known to activate, via PDK1, the powerful protective pathway stemming from Akt/PKB. ${ }^{31,32}$ This explains why PI3-K inhibitors generally promote cell death rather than protecting against it, ${ }^{33}$ although they have been found to protect against both necrosis ${ }^{34}$ and autophagic cell death ${ }^{35}$ in a cardiomyocyte-derived cell line; surprisingly, these exceptional cases of protection appear to have been due to inhibition of class I PI3-K, since overexpression of class I PI3-K enhanced cell death. ${ }^{34,35}$ Thus, in the absence of direct evidence on the class of PI3-K involved in our present protection phenomena, interpretation is difficult; the most likely candidate is class III (mammalian VPS34) but class I cannot be excluded.

\section{Evidence for the causal implication of a lysosomal pathway}

The fact that specific $\mathrm{PI} 3-\mathrm{K}$ inhibitors diminish the (mainly autophagic) cell death in our model is relevant to the question of whether autophagy is really instrumental in "autophagic" cell death, or whether it is an epiphenomenon (or even protective). Claims for an instrumental role have so far depended largely on the fact that cell death characterized by pronounced autophagy is in numerous situations prevented or delayed by treatment with 3-MA. ${ }^{12,15,36-38}$ The confirmation of this protection with specific PI3-K inhibitors implies that it is not due to some unknown nonspecific effect of 3-MA, but is indeed due to inhibition of PI3-K (probably class III). It remains possible that the key PI3-K-dependent cellular event may not be autophagy itself, since class III PI3-K plays a role in various other membrane trafficking events including endosome fusion and the channeling of lysosomal hydrolases to lysosomes. ${ }^{39}$ Thus, although the present results do not prove that autophagy itself is responsible for the cell death, they do indicate that a lysosome/trafficking-related mechanism is heavily involved, supporting the conclusions of Uchiyama's group based mainly on the prevention of this cell death by 


\section{A. Guillon-Munos et al.}

Figure 6. Evaluation of caspase-3 activation by immunoblotting. (a) Time course of caspase-3 activation in the presence of LY294002 or z-VAD.fmk; (b) Quantification of caspase-3 activation. Plot represents average values \pm SEM from samples collected after $12(n=2)$, $16(n=3), 20(n=3)$ and $24(n=4) \mathrm{h}$ treatment. Values are normalized with respect to the $24 \mathrm{~h}$ control (serum-deprived, no drug) condition. (c) Effect of LY294002 or 3MA on caspase-3 expression and activation after $24 \mathrm{~h}$ of culture. IB, immunoblot; FL, full length. Statistical comparisons were by one-tailed $t$-test. A value of $p<0.05$ was considered significant: * $\mathrm{LY}$ vs. control; \#LY vs $z$-VAD; $£$ control vs z-VAD.

a

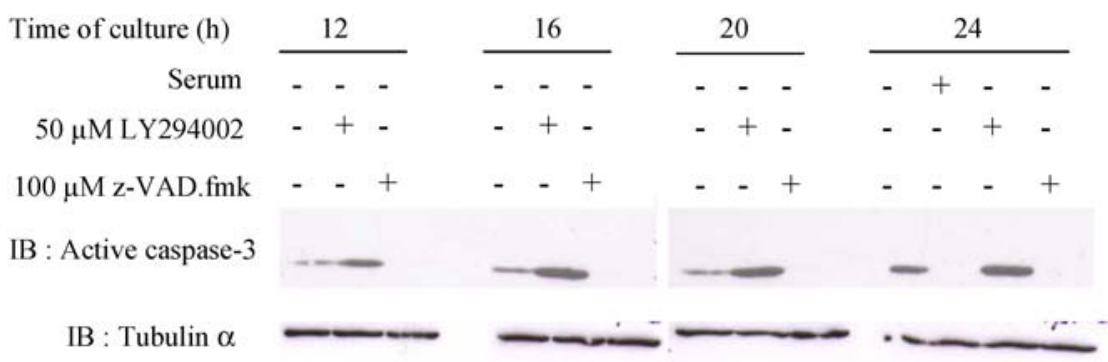

b

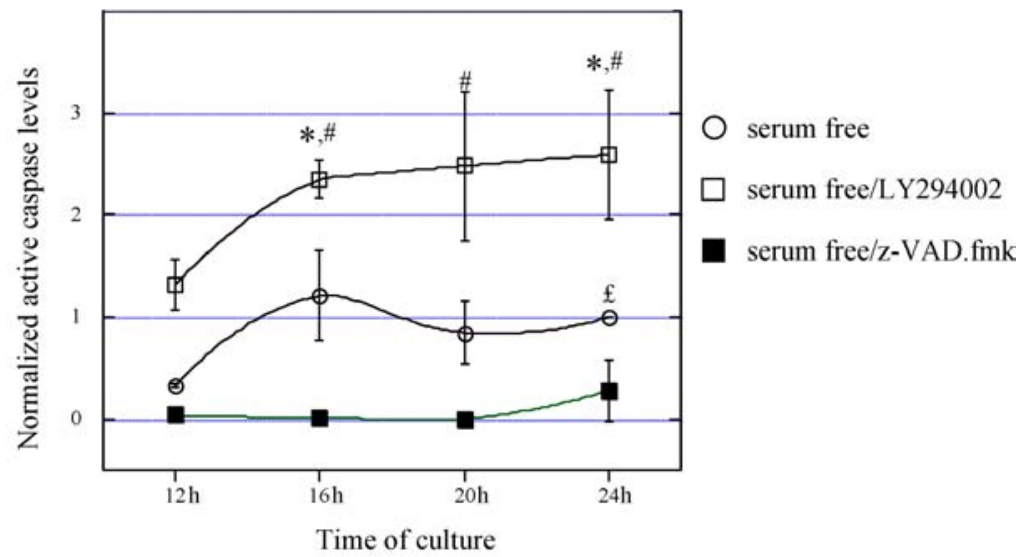

$\mathrm{C}$

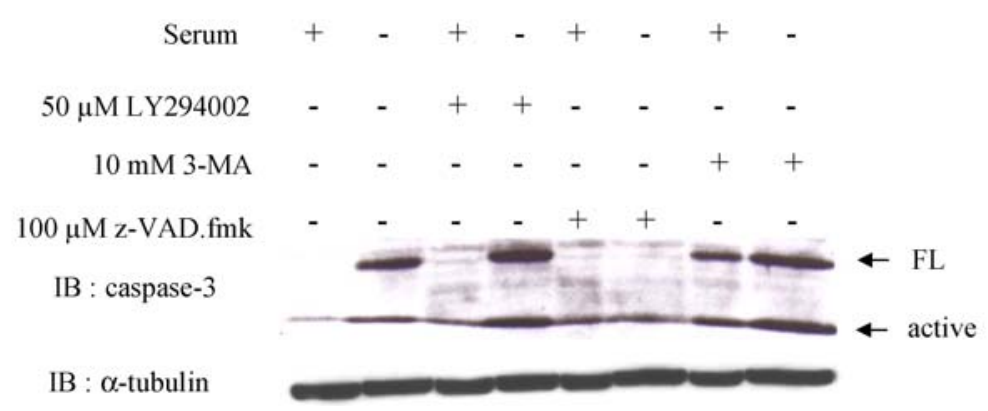

inhibition or deletion of the lysosomal protease cathepsin $\mathrm{D}$, and on its antagonism by cathepsin B. ${ }^{40,13}$ Moreover, a death-mediating role for the autophagic pathway has very recently been shown in two outstanding papers in which the autophagic, non-apoptotic death of fibroblasts was prevented by reducing the expression of autophagy genes ATG5, ATG6 (Beclin 1) and ATG7 by means of RNA-interference. ${ }^{41,42}$

\section{Apoptotic and autophagic death pathways, and their interactions}

If it can be accepted that autophagy (or a closely related trafficking event) is truly instrumental in autophagic cell death, the next question is the relation between the autophagy-related death mechanism and the apoptotic mechanism that was also active, and could be observed 
quite often in the very same cell. There is evidence in some cases for shared mechanisms and cross-talk between the apoptotic and autophagic death pathways ${ }^{43}$ but also for a mechanism for switching between the two pathways ${ }^{44}$ that may explain why in many cases a single mechanism predominates in a given cell. ${ }^{6,9,11,45-47}$

The present model involved both autophagic and apoptotic features, in line with previous evidence from the same PC12 sub-line showing autophagy and activation of lysosomal cathepsins, but also apoptotic characteristics including clumping of chromatin, activation of caspase3 , moderate protection by acetyl-DEVD.cho (an inhibitor of caspase-3-like proteinases), and strong protection by zVAD.fmk. ${ }^{13,14,17,40}$

The question therefore arises whether the autophagic and apoptotic characteristics are caused by separate death pathways acting in different cells or in parallel in the same cell, or whether the autophagy is merely an upstream trigger of caspase- 3 activation, or a downstream effector.

Our data on the timing of the appearance of apoptotic and autophagic features are indecisive. While a statistically significant increase in AcP-positive cells occurred within $12 \mathrm{~h}$ of serum-deprivation (Figure $2 \mathrm{~b}$ ), well before the first statistically significant increase in the number of pyknotic cells (Figure 2c), this was paralleled by an early activation of caspase- 3 by $12 \mathrm{~h}$.

In contrast, our pharmacological data do indicate that the role of PI3-K-dependent events (such as autophagy) in the cell death is as a separate death pathway and not as an upstream trigger of caspase- 3 activation, nor as a downstream effector. The upstream trigger hypothesis is contradicted by the fact that blockade of autophagy by PI3-K inhibition, far from reducing caspase-3 activation, strongly increased it, but nevertheless protected the cells. The increase in caspase activation was probably caused by inhibition of class I PI3-K, and hence of the Akt pathway, which is strongly inhibitory to caspase $-3 .{ }^{48}$ That the autophagy was not downstream of caspase activation (as can occur in insect development), ${ }^{43}$ was inherently unlikely in serum-deprived PC12 cells, where lysosomal changes occur very early (changed proteolytic activities of cathepsins B, D and L occur within $3 \mathrm{~h}$ of serumdeprivation), ${ }^{13}$ and can be ruled out by our own observation that $z$-VAD.fmk failed to affect the numbers of cells with acid phosphatase-positive granules. The most plausible alternative is that the apoptotic and autophagic death pathways act essentially in parallel within a given cell (or, less likely, in different cells) and with distinct characteristics. This fits in perfectly with our observation that $z$-VAD.fmk was more effective than the PI3-K inhibitors in reducing the numbers of pyknotic cells but was less effective in promoting their survival measured at $24 \mathrm{~h}$; this could mean either that z-VAD.fmk switches cells from a purely apoptotic pathway to an autophagic death pathway involving minimum chromatin condensa- tion, or that both pathways were often active in parallel in the same cell and that z-VAD.fmk blocked the apoptotic one (reducing chromatin condensation) but failed to protect because the autophagic pathway was unaffected. There was previous evidence that cells in which apoptosis is blocked by a caspase-inhibitor can die by an alternative, 3-MA-dependent nonapoptotic mechanism involving autophagy but not chromatin condensation, ${ }^{15}$ and it has recently been shown that z-VAD.fmk can even induce autophagic cell death, again with little if any chromatin condensation. $^{41}$

In asserting that PI3-K-dependent autophagy mediates autophagic cell death by a pathway separate from the canonical, caspase-3-mediated apoptotic pathway in the present model, we are not denying that lysosomal events can trigger apoptosis in other situations (e.g. $\left.{ }^{49,1}\right)$. Even in the present model lysosomal events may do so, ${ }^{17}$ but by a PI3-K-independent pathway.

\section{Conclusions}

Our data indicate that autophagy, or at least a PI3-Kmediated event related to autophagy, is instrumental in the death of serum-deprived PC12 cells, and that the apoptotic and autophagic features of these cells reflect parallel death pathways, not sequential events in the same pathway.

\section{Acknowledgments}

We thank Eve Danthe and Vincent Mottier for technical assistance, Christian Widmann for advice and cell biology facilities, Prof. Jean Gruenberg for the 6C4 antibody against LBPA, Prof. Tamutso Yoshimori for his antibody against Vps34, Prof. Yasuo Uchiyama for PC12 cells and comments on the manuscript, and Dr. Patrice Codogno for advice.

\section{References}

1. Ogier-Denis E, Codogno P. Autophagy: A barrier or an adaptive response to cancer. Biochim Biophys Acta-Reviews on Cancer 2003; 1603: 113-128.

2. Blommaart EFC, Krause U, Schellens JPM, VreelingSindelárová H, Meijer AJ. The phosphatidylinositol 3-kinase inhibitors wortmannin and LY294002 inhibit autophagy in isolated rat hepatocytes. Eur J Biochem 1997; 243: 240-246.

3. Petiot A, Ogier-Denis E, Blommaart EFC, Meijer AJ, Codogno P. Distinct classes of phosphatidylinositol 3'-kinases are involved in signaling pathways that control macroautophagy in HT-29 cells. J Biol Chem 2000; 275: 992-998.

4. Cuervo AM. Autophagy: In sickness and in health. Trends Cell Biol 2004; 14: 70-77. 
5. Clarke PGH. Developmental cell death: Morphological diversity and multiple mechanisms. Anat Embryol 1990; 181: 195213.

6. Knaapen MWM, Davies MJ, De Bie M, Haven AJ, Martinet W, Kockx MM. Apoptotic versus autophagic cell death in heart failure. Cardiovasc Res 2001; 51: 304-312.

7. Borsello T, Croquelois K, Hornung JP, Clarke PGH. Nmethyl-D-aspartate-triggered neuronal death in organotypic hippocampal cultures is endocytic, autophagic and mediated by the c-Jun N-terminal kinase pathway. Eur J Neurosci 2003; 18: 473-485.

8. Nixon RA, Cataldo AM, Mathews PM. The endosomallysosomal system of neurons in Alzheimer's disease pathogenesis: A review. Neurochem Res 2000; 25: 1161-1172.

9. Kitanaka C, Kuchino Y. Caspase-independent programmed cell death with necrotic morphology. Cell Death Differ 1999; 6: 508-515.

10. Bursch W, Hochegger K, Török L, Marian B, Ellinger A, Hermann RS. Autophagic and apoptotic types of programmed cell death exhibit different fates of cytoskeletal filaments. $J$ Cell Sci 2000; 113: 1189-1198.

11. Yanagisawa H, Miyashita T, Nakano Y, Yamamoto D. HSpin1, a transmembrane protein interacting with $\mathrm{Bcl}-2 / \mathrm{Bcl}-\mathrm{x}_{L}$, induces a caspase-independent autophagic cell death. Cell Death Differ 2003; 10: 798-807.

12. Bursch W, Ellinger A, Kienzl H, et al. Active cell death induced by the anti-estrogens tamoxifen and ICI 164384 in human mammary carcinoma cells (MCF-7) in culture: The role of autophagy. Carcinogenesis 1996; 17: 1595-1607.

13. Isahara K, Ohsawa Y, Kanamori S, et al. Regulation of a novel pathway for cell death by lysosomal aspartic and cysteine proteinases. Neuroscience 1999; 91: 233-249.

14. Ohsawa Y, Isahara K, Kanamori S, et al. An ultrastructural and immunohistochemical study of PC12 cells during apoptosis induced by serum deprivation with special reference to autophagy and lysosomal cathepsins. Arch Histol Cytol 1998; 61: 395-403.

15. Xue LZ, Fletcher GC, Tolkovsky AM. Autophagy is activated by apoptotic signalling in sympathetic neurons: An alternative mechanism of death execution. Molec Cell Neurosci 1999; 14: 180-198.

16. Martin DN, Baehrecke EH. Caspases function in autophagic programmed cell death in Drosophila. Development 2004; 131: 275-284.

17. Uchiyama Y. Autophagic cell death and its execution by lysosomal cathepsins. Arch Histol Cytol 2001; 64: 233-246.

18. Clarke PGH. Identical populations of phagocytes and dying neurons revealed by intravascularly injected horseradish peroxidase, and by endogenous glutaraldehyde-resistant acid phosphatase, in the brains of chick embryos. Histochem J 1984; 16: 955-969.

19. Pearse AGE. Histochemistry, Theoretical and Applied, vol.1. Edinburgh, London, New York: Churchill Livingstone 1968.

20. Kobayashi T, Stang E, Fang KS, de M, Parton RG, Gruenberg J. A lipid associated with the antiphospholipid syndrome regulates endosome structure and function. Nature. 1998; 392: 193-197.

21. Kihara A, Kabeya Y, Ohsumi Y, Yoshimori T. Beclinphosphatidylinositol 3-kinase complex functions at the transGolgi networkBeclin-phosphatidylinositol 3-kinase complex functions at the trans-Golgi network. EMBO Reports 2001; 2: 330-335.

22. Hornung JP, Koppel H, Clarke PGH. Endocytosis and autophagy in dying neurons: An ultrastructural study in chick embryos. J Comp Neurol 1989; 283: 425-437.
23. Clarke PGH, Oppenheim RW. Neuron death in vertebrate development: In vivo methods. Methods Cell Biol 1995; 46: 277321.

24. Tassa A, Roux MP, Attaix D, Bechet DM. Class III phosphoinositide 3-kinase-Beclin 1 complex mediates the amino aciddependent regulation of autophagy in $\mathrm{C}_{2} \mathrm{C}_{12}$ myotubes. Biochem J 2003; 376: 577-586.

25. Foster FM, Traer CJ, Abraham SM, Fry MJ. The phosphoinositide (PI) 3-kinase family. J Cell Sci 2003; 116: 3037-3040.

26. Seglen PO, Gordon PB. 3-Methyladenine: Specific inhibitor of autophagic/lysosomal protein degradation in isolated rat hepatocytes. Proc Nat Acad Sci USA 1982; 79: 1889-1892.

27. Fruman DA, Meyers RE, Cantley LC. Phosphoinositide kinases. Annu Rev Biochem 1998; 67: 481-507.

28. Davies SP, Reddy H, Caivano M, Cohen P. Specificity and mechanism of action of some commonly used protein kinase inhibitors. Biochem J 2000; 351: 95-105.

29. Stein RC, Waterfield MD. PI3-kinase inhibition: A target for drug development? Mol Med Today 2000; 6: 347-357.

30. Takegawa K, DeWald DB, Emr SD. Schizosaccharomyces pombe Vps34p, a phosphatidylinositol-specific PI 3-kinase essential for normal cell growth and vacuole morphology. J Cell Sci 1995; 108: 3745-3756.

31. Marte BM, Downward J. PKB/Akt: Connecting phosphoinositide 3-kinase to cell survival and beyond. Trends Biochem Sci 1997; 22: 355-358.

32. Luo HR, Hattori H, Hossain MA, et al. Akt as a mediator of cell death. Proc Natl Acad Sci USA 2003; 100: 1171211717.

33. Spear N, Estevez AG, Barbeito L, Beckman JS, Johnson GV. Nerve growth factor protects PC12 cells against peroxynitriteinduced apoptosis via a mechanism dependent on phosphatidylinositol 3-kinase. J Neurochem 1997; 69: 53-59.

34. Aki T, Mizukami Y, Oka Y, et al. Phosphoinositide 3-kinase accelerates necrotic cell death during hypoxia. Biochemical J 2001; 358: 481-487.

35. Aki T, Yamaguchi K, Fujimiya T, Mizukami Y. Phosphoinositide 3-kinase accelerates autophagic cell death during glucose deprivation in the rat cardiomyocyte-derived cell line $\mathrm{H} 9 \mathrm{c} 2$. Oncogene 2003; 22: 8529-8535.

36. Sandvig K, van Deurs B. Toxin-induced cell lysis: Protection by 3-methyladenine and cycloheximide. Exp Cell Res. 1992; 200: 253-262.

37. Jia L, Dourmashkin RR, Allen PD, Gray AB, Newland AC, Kelsey SM. Inhibition of autophagy abrogates tumour necrosis factor $\alpha$ induced apoptosis in human T-lymphoblastic leukaemic cells. Br J Haematol 1997; 98: 673-685.

38. Jia L, Dourmashkin RR, Newland AC, Kelsey SM. Mitochondrial ultracondensation, but not swelling, is involved in TNF alpha-induced apoptosis in human T-lymphoblastic leukaemic cells. Leukemia Res 1997; 21: 973-983.

39. Brown WJ, DeWald DB, Emr SD, Plutner H, Balch WE. Role for Phosphatidylinositol 3-Kinase in the Sorting and Transport of Newly Synthesized Lysosomal-Enzymes in MammalianCells. J Cell Biol 1995; 130: 781-796.

40. Shibata M, Kanamori S, Isahara K, et al. Participation of cathepsins B and D in apoptosis of PC12 cells following serum deprivation. Biochem Biophys Res Comm 1998; 251: 199-203.

41. Yu L, Alva A, Su H, et al. Regulation of an ATG7-beclin 1 program of autophagic cell death by caspase-8. Science 2004; 304: 1500-1502.

42. Shimizu S, Kanaseki T, Mizushima N, et al. Role of Bcl-2 family proteins in a non-apoptotic programmed cell death dependent on autophagy genes. Nature Cell Biol 2004; 6: 12211228. 
43. Lee CY, Baehrecke EH. Steroid regulation of autophagic programmed cell death during development. Development 2001; 128: $1443-1455$.

44. Piacentini M, Evangelisti C, Mastroberardino PG, Nardacci $\mathrm{R}$, Kroemer G. Does prothymosin- $\alpha$ act as molecular switch between apoptosis and autophagy? Cell Death Differ 2003; 10: 937-939.

45. Chi SJ, Kitanaka C, Noguchi K, et al. Oncogenic Ras triggers cell suicide through the activation of a caspase-independent cell death program in human cancer cells. Oncogene. 1999; 18: 2281-2290.

46. Zaidi AU, D'Sa-Eipper C, Brenner J, et al. Bcl- $\mathrm{X}_{L}$-Caspase9 interactions in the developing nervous system: Evidence for multiple death pathways. I Neurosci 2001; 21: 169175 .

47. Guimaraes CA, Benchimol M, Amarante-Mendes GP, Linden R. Alternative programs of cell death in developing retinal tissue. J Biol Chem 2003; 278: 41938-41946.

48. Shimoke K, Chiba H. Nerve growth factor prevents 1-methyl4-phenyl-1,2,3,6-tetrahydropyridine-induced cell death via the Akt pathway by suppressing caspase-3-like activity using PC12 cells: Relevance to therapeutical application for Parkinson's disease. J Neurosci Res 2001; 63: 402-409.

49. Kagedal K, Zhao M, Svensson I, Brunk UT. Sphingosineinduced apoptosis is dependent on lysosomal proteases. Biochem J 2001; 359: 335-343. 